Research Paper

\title{
Industrial Noise and Tooth Wear - Experimental Study
}

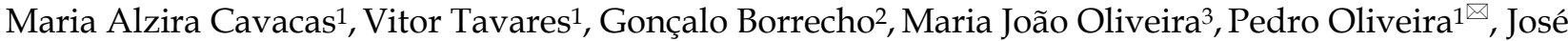 \\ Brito $^{4}$, Artur Águas ${ }^{3}$, José Martins dos Santos ${ }^{1}$ \\ 1. Anatomy Department, Center for Interdisciplinary Research Egas Moniz, Health Sciences Institute, Monte de Caparica, Portugal; \\ 2. Pathology Department, Hospital Santa Maria, Lisboa, Portugal; \\ 3. Anatomy Department, Abel Salazar Biomedical Health Institute, Porto, Portugal; \\ 4. Statistics Department, Center for Interdisciplinary Research Egas Moniz, Health Sciences Institute, Monte de Caparica, Portugal.
}

$\triangle$ Corresponding author: Pedro Oliveira, Phone: 00351 936983136/ 00351212946800 Facsimile: 00351212946868 E-mail: jsantos@egasmoniz.edu.pt or pedromaoliveira@hotmail.com.

() 2015 Ivyspring International Publisher. Reproduction is permitted for personal, noncommercial use, provided that the article is in whole, unmodified, and properly cited. See http://ivyspring.com/terms for terms and conditions.

Received: 2014.12.10; Accepted: 2015.02.01; Published: 2015.02.27

\begin{abstract}
Tooth wear is a complex multifactorial process that involves the loss of hard dental tissue. Parafunctional habits have been mentioned as a self-destructive process caused by stress, which results in hyperactivity of masticatory muscles. Stress manifests itself through teeth grinding, leading to progressive teeth wear. The effects of continuous exposure to industrial noise, a "stressor" agent, cannot be ignored and its effects on the teeth must be evaluated.

Aims: The aim of this study was to ascertain the effects of industrial noise on dental wear over time, by identifying and quantifying crown area loss.

Material and Methods: 39 Wistar rats were used. Thirty rats were divided in 3 experimental groups of 10 animals each. Animals were exposed to industrial noise, rich in LFN components, for 1, 4 and 7 months, with an average weekly exposure of 40 hours $(8 \mathrm{~h} /$ day, 5 days/week with the weekends in silence). The remaining 9 animals were kept in silence. The areas of the three main cusps of the molars were measured under light microscopy.

Statistical analysis used: A two-way ANOVA model was applied at significance level of $5 \%$.

Results: The average area of the molar cusps was significantly different between exposed and non-exposed animals. The most remarkable differences occurred between month 1 and 4 . The total crown loss from month 1 to month 7 was $17.3 \%$ in the control group, and $46.5 \%$ in the exposed group, and the differences between these variations were significant $(p<0.001)$.

Conclusions: Our data suggest that industrial noise is an important factor in the pathogenesis of tooth wear.
\end{abstract}

Key words: tooth wear, industrial noise, low frequency noise, stress, parafunctional habits, bruxism.

\section{Introduction}

Dental wear is a complex multifactorial process that involves the loss of hard dental tissue, specifically enamel and dentin (1).

The prevalence of dental wear, being as sign of normal ageing, has increased, as the average life expectancy of the population is also increasing with natural teeth being retained longer than in past generations.

The mechanical causes and the parafunctional habits (like bruxism) are the most commonly reported factors associated with dental wear. Mechanical fac- tors, such as toothbrush abrasion, tongue friction and attrition have been accepted as causes of enamel loss (2). Additionally, chronic regurgitation of gastric acids in patients with gastro-esophageal reflux disease may cause dental erosion, which can lead, in combination with attrition or bruxism, to extensive loss of coronal tooth tissue (3). Tooth grinding may also cause severe damage not only to enamel and dentin, but also on the patient's temporomandibular joint $(4,5)$.

A correlation was found between exposure to 
noise and parafunctions (6). Parafunctional habits have been reported by many researchers as a self-destructive process caused by stress. According to these studies (7-11), excessive stress results in hyperactivity of masticatory muscles, which manifests itself through various parafunctional activities, in particular teeth grinding, leading to progressive abrasion of the teeth (6).

Emotional problems, such as anxiety, anger and depression, may result in bruxism behavior. Sleep bruxism is common in the general population and represents the third most frequent parasomnia (12). Bruxism has numerous consequences, which are not limited to dental or muscular problems. Among the associated risk factors, patients with anxiety and sleep disordered breathing have a higher number of risk factors for sleep bruxism (12).

Slavicek stated that the explanations of parafunctions are concerned with viewing and tolerating the masticatory organ as a "psychic stress valve" (13).

There is sufficient evidence, from large-scale epidemiological studies (14-16), linking the population's exposure to environmental noise to adverse health effects.

According to the results from the Environmental Burden of Disease (EBD) in Europe, a project in six European countries (17) reported at the World Health Organization (WHO) Ministerial Conference held in Parma in March 2010, traffic noise, rich in low frequency noise (LFN) components, was ranked second among the selected environmental stressors, evaluated in terms of their public health impact in those six European countries. The trend is that noise exposure is increasing in Europe compared to other stressors (e.g. exposure to second hand smoke, dioxins and benzene), which have been declining.

On the other hand, LFN is present in professional, residential, and leisure environments, and is not adequately measured with standard methods. Typically, LFN is not assessed during routine noise evaluations that are measured in $\mathrm{dBA}$; according to the WHO (17), LFN should be measured in dBLin (unweighted) and defined as low spectral energy, bandwidth up to $500 \mathrm{~Hz}$ and amplitude of 80-110 dB.

It is currently known that LFN affects several organs and systems, like the heart (18), lung (19), stomach or duodenum $(20,21)$, inducing the proliferation of extracellular matrices and cellular degeneration in the absence of inflammatory process. As an environmental "stressor" agent, the effects of LFN cannot be ignored and its effects on the teeth must be considered.

Our aim was to study the effects of industrial noise on dental wear over the time. Our null hypothesis is that industrial noise does not affect crown area loss (enamel and dentin).

\section{Materials and Methods}

\section{Animals}

39 male Wistar rats were used, from a Spanish producer (Charles River Laboratories España SA, Spain). All animals were fed normally and had free access to water, received treatment in accordance with the laws of the European Union for the protection of animals $\left(1005 / 92 / 23^{\text {rd Out }) ~ a n d ~ t h e ~ I n t e r d i s c i p l i n a r y ~}\right.$ Principles and Guidelines for the Use of Animals in Research. They were kept under normal conditions and placed in groups of two inside a plastic box $(42 \times 27 \times 16 \mathrm{~cm})$ with a steel cover.

\section{Noise Exposure}

The environmental noise of a cotton-mill room from a large textile factory was used as the paradigm of the occupational noise. The noise present in this cotton mill room was recorded and reproduced according to the procedure used by Oliveira et al., (22, 23).

The spectrum of frequencies and amplitude of noise used is documented in (Figure 1).

Thirty rats were exposed to noise, and nine were used as age-matched controls.

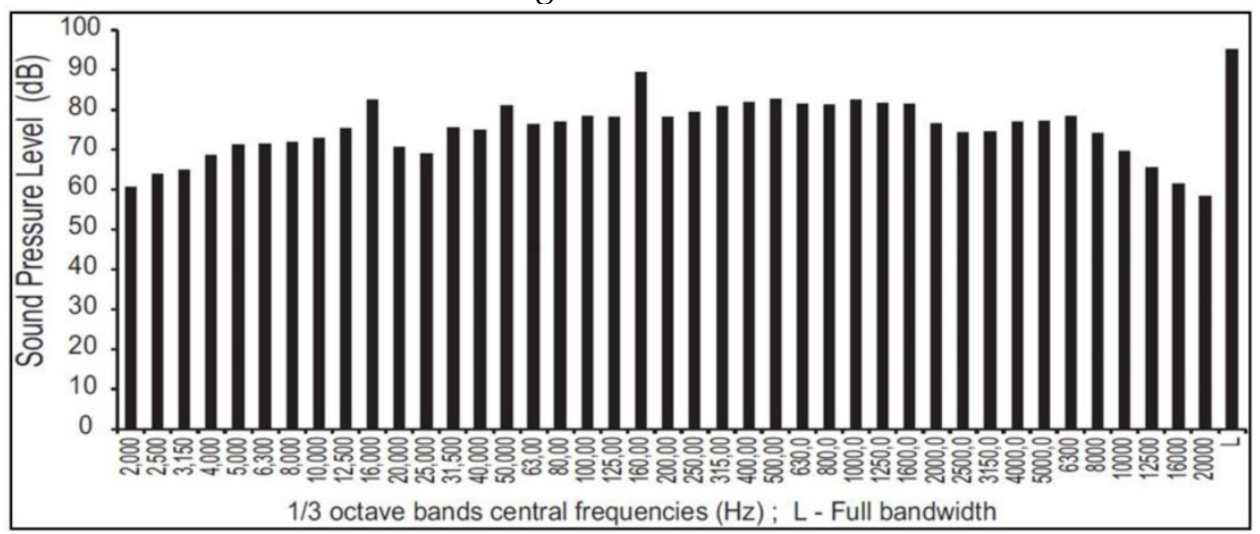

Figure 1. Noise spectrum. 
Rats exposed to noise were submitted to different periods of noise exposure, ranging from 1 to 7 months, according to an occupationally simulated time schedule (8h/day, 5 days/week with the weekends in silence). The thirty rats were divided into three groups and sacrificed after 1, 4 and 7 months of noise exposure. They were, therefore, 3, 6 and 9 months old when they were sacrificed. The remaining 9 Wistar rats were used as age-matched controls (no noise exposure) and thus sacrificed when they were 3 , 6 and 9 months old.

After the reported periods, rats were sacrificed, together with 3 rats from the control group, with a lethal intraperitoneal injection of sodium pentobarbital.

The first and the second upper and lower molars of each animal were extracted. 126 out of the 240 extracted teeth were studied; the remaining was discarded due to fractures of the crown and/or root, during the extraction procedures.

The teeth were preserved in 10\% buffered formalin, and processed for light microscopy. Sections were stained with Hematoxylin Eosin (HE).

The area of the three main cusps of each tooth was measured: the mesial cusp, the central cusp and the distal cusp.

\section{Measurements}

All the images of the sections were obtained with a magnification of 40x using a Leica DMLB microscope (Leica Microsystems CMS GmbH, Wetzlar, Germany).

The data analysis was performed with the LAS (Leica Application Suite) software.

Individual cusp base areas were measured by tracing the outline of the cusp, following the occlusal surface to the tangential line cross the highest point of the pulp horn (Figure 2). The cusps that had unclear or damaged outline were excluded.

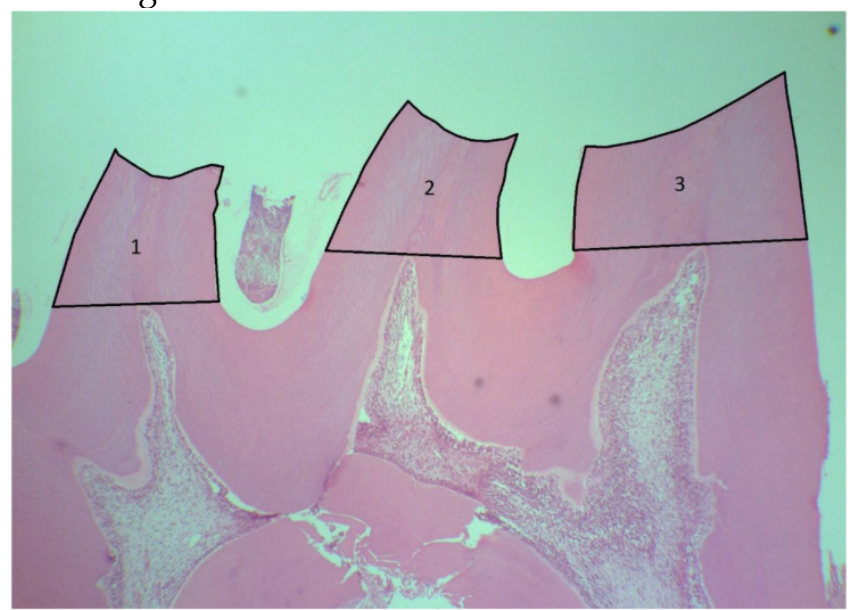

Figure 2. Area measurements procedure (1 - distal cusp; 2 - central cusp; 3 -mesial cusp). HE40x
All the measurements were performed by the same observer. Each blinded measurement was repeated 3 times, in three different days, and the average was calculated and used to statistically analyze the data.

\section{Statistical analysis}

Statistical analysis was performed with the SPSS 19.0 software (SPSS Inc., Chicago, IL, USA). All statistical tests were applied at the significance level of $5 \%$.

A two-way ANOVA model was fit to the data after checking model assumptions, in which the dependent variable was defined as the average of the 3 cusp areas. The two independent factors were Time (1, 4 and 7 months) and Group (Exposed and Control groups). The assumption of homogeneity of variance was checked using the Levene test. Concerning normality of the distribution of the dependent value, and given the small size of the classes, it was sufficient to confirm the symmetry of the variable, as the F ratio is robust in such conditions.

\section{Results}

The HE sections of the control groups 1 and 4 displayed a normal appearance of the teeth, namely intact cusps without signs of wear (Figure 3).

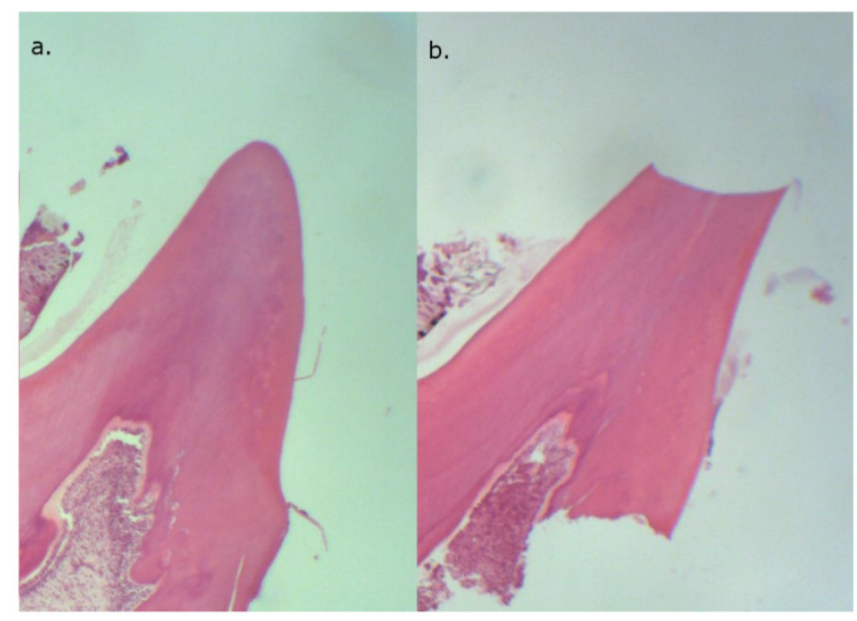

Figure 3. a. control group at 4 months (HE40x). Distal cusp without occlusal wear; b. control group at 7 months (HE40x). Distal cusp with discrete occlusal wear.

The teeth of control group 7 showed a total crown loss of $17.3 \%$ compared to control 1 and of $17.5 \%$ when compared to control group 4 (Figure 4 and Table 1).

Wear was observed in the sections from the groups exposed to noise.

Table 2 displays the two-way ANOVA results for the average area of all cusps. The results show that the average area differs significantly between exposed and non-exposed animals, that the area also varies 
significantly with time, and that variation is significantly different between groups. Moreover, the model fit to the data is good, as expressed by the R Squared value $(0.668)$.

Table 1 presents the estimated mean values of average areas in the classes defined by main factors, also depicted in Figure 4.

Table 1. Estimated marginal means of average area. Dependent Variable: average_area.

\begin{tabular}{|c|c|c|c|c|c|}
\hline \multirow[b]{3}{*}{ Time } & \multicolumn{5}{|l|}{ Group } \\
\hline & \multirow[b]{2}{*}{ control } & \multirow[t]{2}{*}{ Mean $^{\mathrm{a}}$} & \multirow[t]{2}{*}{ S.E.M. } & \multicolumn{2}{|c|}{ Within group variation $(\%)^{b}$} \\
\hline & & & & To time $=1$ & To time $=4$ \\
\hline \multirow[t]{2}{*}{1} & control & 250662.861 & 11258.752 & - & - \\
\hline & exposed & $\begin{array}{l}235052.165 \\
(p=0.331)\end{array}$ & 11258.752 & - & - \\
\hline \multirow[t]{2}{*}{4} & control & 251476.163 & 11258.752 & +0.3 & - \\
\hline & exposed & $\begin{array}{l}142855.392 \\
(p<0.001)\end{array}$ & 11258.752 & $\begin{array}{l}-39.2 \\
(p<0.001)\end{array}$ & - \\
\hline \multirow[t]{2}{*}{7} & control & 207392.995 & 10277.787 & -17.3 & -17.5 \\
\hline & exposed & $\begin{array}{l}125712.686 \\
(p<0.001)\end{array}$ & 9874.579 & $\begin{array}{l}-46.5 \\
(p<0.001)\end{array}$ & $\begin{array}{l}-12.0 \\
(p=0.212)\end{array}$ \\
\hline
\end{tabular}

a. Significance $(p)$ in tests of interactive effect.

b. Significance $(p)$ in planned contrasts.

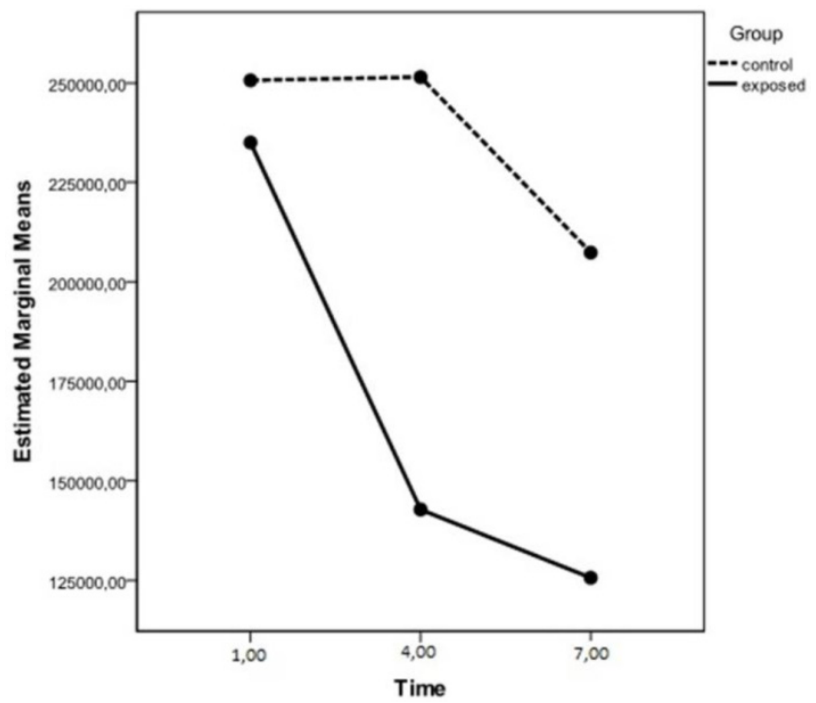

Figure 4. Estimated marginal means of average area.

Table 2. Tests of Between-Subjects Effects.

\begin{tabular}{|c|c|c|c|}
\hline \multicolumn{4}{|c|}{ Dependent Variable: average_area } \\
\hline Effect & $\mathrm{F}$ & Sig. & Observed Powerb \\
\hline Time & 25.561 & $<0.001$ & 1.000 \\
\hline Group & 59.703 & $<0.001$ & 1.000 \\
\hline Time * Group & 9.111 & $<0.001$ & 0.969 \\
\hline
\end{tabular}

There is a significant interaction, identified by the different slopes of the lines in Figure 4, which made it necessary to conduct planned contrasts for the interactive and main effects. In what concerns the interactive effect, the planned contrasts show that, at month 1, the mean cusp area does not differ significantly between exposed and non-exposed animals $(p=0.331)$, whereas at months 4 and 7 , the mean cusp area is significantly lower in exposed animals $(\mathrm{p}<$ $0.001)$.

Regarding time variations, the planned contrasts show that, between month 1 and 4, the observed variation in control cusp areas $(0.3 \%$ increase) is significantly different $(p<0.001)$ from that observed in the exposed group (39.2\% decrease). Between month 4 and month 7 , the observed variation in cusp areas in the control group (17.5\% decrease) is not significantly differently $(\mathrm{p}=0.212)$ from the exposed group $(12.0 \%$ decrease).

From the magnitude and statistical significance of the contrasts, the most noticeable differences occurred between month 1 and 4 .

The total crown loss from month 1 to month 7 was a $17.3 \%$ decrease in the control group and $46.5 \%$ decrease in the exposed group, and the differences between these variations were statistically significant $(\mathrm{p}<0.001)$.

\section{Discussion}

All tissues are influenced by the processes of ageing (24). This influence is more evident under functional and irritant stimuli in teeth (25). Wear may result from physiological or from pathological conditions. Tooth wear is irreversible and, unless the causes are detected and dealt with, it may progress in severity with age $(25,26)$. Early diagnosis, prevention and intervention are the basis for tooth wear management (27).

Dental wear is a multifactorial condition. The mechanical causes and parafunctional habits are the most reported in the literature. Among the deleterious habits, bruxism, associated with abrasion, is the most common.

Bruxism is an oral habit characterized by a rhythmic activity of the temporomandibular muscles that causes a forced contact between dental surfaces. It is accompanied by tooth clenching or grinding that can be loud enough to be heard (12). The grinding of teeth has long been held as one physical manifestation of stress and anxiety (28).

Our study revealed a serious problem of tooth wear amongst the rats exposed to LFN.

The occlusal wear found in the aged-matched controls is certainly related to the normal ageing process as the animals were fed the same food and were in a silent environment.

There was a noticeable and significant crown wear rate in the group exposed to LFN for 4 months, 
which resulted in a 39\% reduction in the average areas of the molar cusps. Crown loss rate was attenuated in the 7 month group.

Other studies have recognized the relationship between LFN and stress (29-31). In most studies, the relationship between noise as a "stressful" agent and the activity of the muscles of mastication suggests that the prevalence of dental abrasion in individuals subjected to noise is very high. Studies in workers of the textile industry (32) reported significantly higher probability ratios of teeth with abrasion in the groups exposed to noise in comparison with the control group.

In fact, stress and the stress adaptation mechanisms must be considered. The first stress response induced pathway is the activation of the hypothalamic-pituitary-adrenal (HPA) axis, which promotes the liberation of hormones that stimulate the release of glucocorticoids from the adrenal cortex (31).

The second response pathway is the sympathetic, promoting the liberation of adrenaline and noradrenaline from the adrenal medulla (31).

Several studies clearly separate acute and chronic stress conditions, referring an adaptation/habituation state $(33,34)$.

Habituation is defined as a behavioral response decrement that results from repeated stimulation and that does not involve sensory adaptation/sensory fatigue or motor fatigue (35). It is also known that the magnitude of the HPA activation occurring in response to a stressor declines with repeated exposure to that same stressor $(23,36)$.

These studies may explain our results, specifically the decline in tooth wear with exposure time. Moreover, it cannot be excluded a defensive response to pain or discomfort, caused by wear, with less contact force between teeth.

The teeth response to injuries should also be considered. Repairing, tertiary dentin formation may also play a role, concerning our results.

Unlike secondary dentin, which is physiological and forms throughout the vital life of the tooth, the formation of tertiary dentin is localized in the pulp chamber wall corresponding to the area of the stimulus (37). The tissue that is deposited on the pulpal aspect in response to external stimuli, such as abrasion, attrition, caries, ultra-sonic scaling, among others, is called reactionary tertiary dentin (37). These external factors stimulate an increased rate of matrix secretion by the existing odontoblasts exposed to the influence.

According to Lovschall et al. (38) the cusp wear disturbs the odontoblasts at the tip of the pulp horn, stimulating the deposition of tertiary dentin continuously. This response, in a certain way, compensates the loss of hard tissues from the crown and might justify the attenuation of the values of the wear rate observed in our study after the third month. This wear attenuation, observed from month 4 to month 7 , may also be explained by a decrease in the response of reactionary dentinogenesis with increasing thickness of tertiary dentin being deposited over the pulp chamber wall (37). The distance between odontoblast cells, responsible for producing tertiary dentin, and the dentin tubules, may limit further odontoblast stimulation and cause the measured attenuation in tertiary reactionary dentin production.

LFN induces morphological and functional alterations on the parotid gland from the first week of exposure, which affects the saliva conditions, namely quantitative and qualitative $(39,40)$. Being saliva a very important maintainer of oral homeostasis (41) and, consequently is a tooth protector (42), the susceptibility of teeth to mechanical wear may be increased when secretion of saliva is compromised. LFN also causes lesions similar to periodontitis, as described in a previous study (43). This periodontal condition can also contribute to the decrease in wear rate, as it can cause discomfort and lead to a defensive response with less contact force.

Based on our data, there is significant tooth wear in animals exposed to industrial noise. This wear correlates with exposure time and is significantly higher in the first 4 months of exposure, probably due to mechanisms of adaptation/habituation, defensiveness (periodontitis, pain), to continuous deposition of reactionary tertiary dentin (44), or to a combination of all these factors.

Our results, and the growing presence of noise in the environment, point to the consideration of this stimulus in the pathogenesis of tooth wear.

\section{Competing Interests}

The authors have declared that no competing interest exists.

\section{References}

1. Carranza FA Jr. Periodontologia Clínica de Glickman. $7^{\text {the }}$. McGraw-Hill Interamericana 1993; 2:455-464.

2. Vieira A, Overweg E, Ruben JL, Huysmans MC. Toothbrush abrasion, simulated tongue friction and attrition of eroded bovine enamel in vitro. J Dent 2006; 34:336-342

3. Cengiz S, Cengiz MI, Saraç YS. Dental erosion caused by gastroesophageal reflux disease: a case report. Cases J 2009; 22:8018.

4. Cuccia A, Caradonna C. The relationship between the stomatognathic system and body posture. Clinics 2009; 64:61-66.

5. Sims AB, Stack BC, Demerjian GG. Spasmodic torticollis: the dental connection. Cranio 2012; 30:188-93.

6. Kovacevic M. Role of noise as stress-factor in parafunctions. Stomatol Glas Srb 1989; 36:225-229.

7. Rao SM, Glaros AG. Electromyographic correlates of experimentally induced stress in diurnal bruxists and normal. J Dent Res 1979; 58:1872-8.

8. Clark GT, Rugh JD, Handelman SL. Nocturnal masseter muscle activity and urinary catecholamine levels in bruxers. J Dent Res 1980; 59:1571-6.

9. Rugh JD, Harlan J. Nocturnal bruxism and temporomandibular disorders. Adv Neurol 1988; 49:329-41. 
10. Vanderas AP, Menenakou M, Kouimtzis T, Papagiannoulis L. Urinary catecholamine levels and bruxism in children. J Oral Rehabil 1999; 26:103-10.

11. Rosales VP, Ikeda K, Hizaki K, Naruo T, Nozoe S, Ito G. Emotional stress and brux-like activity of the masseter muscle in rats. Eur J Orthod 2002; 24:107-17.

12. Ohayon MM, Li KK, Guilleminault C. Risk factors for sleep bruxism in the general population. Chest 2001; 119:53-61.

13. Slavicek R. The masticatory organ: Functions and Dysfunctions, $2^{\text {nded. }}$ Klosterneuburg: Gamma Dental Edition 2006; 2:136-138.

14. de Hollander AE, Melse JM, Lebret E, Kramers PG. An aggregate public health indicator to represent the impact of multiple environmental exposures. Epidemiology 1999; 10:606-17.

15. Ndrepepa A, Twardella D. Relationship between noise annoyance from road traffic noise and cardiovascular diseases: a meta-analysis. Noise Health 2011; 13:251-9.

16. Eriksson C, Nilsson ME, Willers SM, Gidhagen L, Bellander T, Pershagen G. Traffic noise and cardiovascular health in Sweden: the roadside study. Noise Health 2012; 14:140-7.

17. [Internet] Parma Declaration on Environment and Health, the Fifth Ministerial Conference on Environment and Health, Parma, Italy, 10-12 March 2010. http://www.euro.who.int/_data/assets/pdf_file/0011/78608/E93618.pdf

18. Antunes E, Oliveira P, Borrecho G, Oliveira MJ, Brito J, Aguas A, Martins dos SJ. Myocardial fibrosis in rats exposed to low frequency noise. Acta Cardiol 2013, 68:241-5

19. Cardoso AP, Oliveira MJ, Silva AM, Aguas AP, Pereira AS. Effects of long term exposure to occupational noise on textile industry workers' lung function. Rev Port Pneumol 2006; 12:45-59.

20. Fonseca J, Martins dos Santos J, Oliveira P, Laranjeira N, Aguas A, Castelo-Branco N. Noise-induced gastric lesions: a light and electron microscopy study of the rat gastric wall exposed to low frequency noise. Arq Gastroenterol 2012, 49:82-88

21. Fonseca J, Martins Dos Santos I, Oliveira P, Laranjeira N, Castelo Branco NA. Noise-induced duodenal lesions: A light and electron microscopy study of the lesions of the rat duodenal mucosa exposed to low frequency noise. Clin Res Hepatol Gastroenterol 2012; 36:72-7.

22. Oliveira MJ, Pereira AS, Ferreira P, Guimarães L, Freitas D, Carvalho A, et al, Arrest in ciliated cell expansion on the bronchial lining of adult rats caused by chronic exposure to industrial noise. Environ Res 2005; 97:282-6.

23. Oliveira MJ, Monteiro MP, Ribeiro AM, Pignatelli D, Águas AP. Chronic exposure of rats to occupational textile noise causes cytological changes in adrenal cortex. Noise Health 2009; 11:118-123.

24. Quirinia A, Viidik A. The influence of age on the healing of normal and ischemic incisional skin wounds. Mech Ageing Dev 1991; 58:221-232.

25. Murray PE, Stanley H, Matthews JB, Sloan AJ, Smith AJ. Age-related odontometric changes of human teeth. Oral Surg Oral Med Oral Pathol Oral Radiol Endod 2002; 93:474-82.

26. Al-Omiri MK, Harb R, Abu Hammad OA, Lamey PJ, Lynch E, Clifford TJ. Quantification of tooth wear: Conventional vs new method using toolmakers microscope and a three-dimensional measuring technique. J Dent 2010; 38: $560-568$

27. Ibbetson R. Tooth surface loss. Treatment planning, Br Dent J, 1999, 186(11):552-558

28. Sutin AR, Terracciano A, Ferrucci L, Costa Jr. PT. Teeth grinding: is emotional stability related to bruxism? J Res Pers 2010; 44:402-405

29. Alves-Pereira M. Noise-induced extra-aural pathology: a review and commentary. Aviat Space Environ Med 1999; 70:7-21

30. Pawlaczyk-Luszczynska M, Dudarewicz A, Waszkowska M, Szymczak W, Sliwinska-Kowalska M. The impact of low frequency noise on mental performance. Int J Occup Environ Health 2004; 18:185-198.

31. Armario A. The hypothalamic-pituitary-adrenal axis: what can it tell us about stressors? CNS Neurol Disord Drug Targets 2006; 5:485-501.

32. Kovacevic M, Belojevic G. Tooth abrasion in workers exposed to noise in the Montenegrin textile industry. Ind Health 2006; 44:481-485.

33. Jones MT, Gillham B. Factors involved in the regulation of adrenocorticotropic hormone/beta-lipoprotic hormone. Physiol Rev 1988; 68:743-818.

34. Pitman DL, Ottenweller JE, Natelson BH. Plasma corticosterone levels during repeated presentation of two intensities of restraint stress: chronic stress and habituation. Physiol Behav 1988; 43:47-55.

35. Rankin CH, Abrams T, Barry RJ, Bhatnagar S, Clayton DF, Colombo J, et al, Habituation revisited: an updated and revised description of the behavioral characteristics of habituation. Neurobiol Learn Mem 2009; 92:135-138.

36. Grissom N, Bhatnagar S. Habituation to repeated stress: get used to it. Neurobiol Learn Mem 2009; 92:215-224.

37. Smith AJ, Cassidy N, Perry H, Bègue-Kirn C, Ruch JV, Lesot H. Reactionary dentinogenesis. Int J Dev Biol 1995; 39:273-8.

38. Lovschall H, Fejerskov O, Josephsen K. Age-related and site-specific changes in the pulpodentinal morphology of rat molars. Arch Oral Biol 2002; 47:361-367.

39. Oliveira P, Pereira da Mata AD, Martins dos Santos JA, da Silva Marques DN, Branco NC, Silveira JM, et al, Low-frequency noise effects on the parotid gland of the Wistar rat. Oral Dis 2007; 13:468-473.

40. Oliveira P, Brito J, Mendes J, da Fonseca J, Águas A, Martins dos Santos J. Effects of large pressure amplitude low frequency noise in the parotid gland perivasculo-ductal connective tissue. Acta Med Port 2013; 26:237-42.

41. Mandel ID. The role of saliva in maintaining oral homeostasis. J Am Dent Assoc 1989; 119:298-304
42. Humphrey SP, Williamson RT. A review of saliva: normal composition, flow, and function. J Prosthet Dent 2001; 85:162-169.

43. Mendes J, Martins dos Santos J, Oliveira P, Castelo Branco NAA. Low Frequency noise effects on the periodontium of the Wistar rat - a light microscopy study. Eur J Anat 2007; 11: 27-30.

44. Cavacas MA, Tavares V, Oliveira MJ, Oliveira P, Sezinando A, Martins dos Santos J. Effects of industrial noise on circumpulpar dentin--a field emission scanning electron microscopy and energy dispersive spectroscopy analysis. Int J Clin Exp Pathol 2013; 6: 2697-702. 